\title{
FORMA DE VIDA OU FORMAS DE VIDA?
}

\author{
Araceli Velloso
}

U niversidade Católica de Goiás

aracelivelloso@uol.com.br

RESU M 0: 0 objetivo principal deste artigo será tornar mais claro o papel desempenhado pela noção de "forma de vida" nos escritos de Ludwig W ittgenstein. Como pano de fundo desta discussão, teremos em mente a questão do emprego do termo "forma de vida" no plural ou apenas no singular. Investigaremos criticamente quatro possíveis interpretações oferecidas por diferentes comentaristas da obra de W ittgenstein. C ada uma delas se aterá a diferentes aspectos da noção de "forma de vida".

Palavras-chave: Formas de vida, W ittgenstein, jogos de linguagem.

INTRODUÇÃO

A noção de "forma devida" não é muito explorada pelos comentaristas de W ittgenstein, e seu papel é considerado por muitos dos seusleitores mais entusiastas como de menor importância e secundário a outras noções mais importantes e mais bem desenvolvidas. N ewton G arver, por exemplo, no seu livro T his complicated form of life, se refere a Max Black como um autor que considera a noção de "forma de vida" de Wittgenstein como propositadamente obscura, "uma expressão deliberadamente vaga, que não tem implicações sérias e para a qual seria um erro procurar maior esclarecimento" (G ARVER, 1994, p. 237). Outros, como Norman Malcolm (1986, p. 91), consideram-na uma noção fundamental. Todos esses filósofos, no entanto, são unânimes em considerar que a fonte de que dispomos para esclarecer o termo "forma de vida" - as passagens da obra publicada de W ittgenstein - é escassa e de difícil compreensão. 
Toda essa controvérsia se deve a doisfatores. 0 primeiro deles é que existe um número muito pequeno de ocorrências do termo "forma de vida" na obra publicada de W ittgenstein, e o segundo é que, além de escassas, as passagens em que o termo ocorre explicitamente não esclarecem com precisão como devemos compreendêlo. Embora só apareça dez vezes na obra publicada do filósofo austríaco ${ }^{1}$ e esteja sujeita a uma enorme con trovérsia, acreditamos que essa tenha sido uma noção central, ainda que por vezes misteriosa e fugidia, entre as preocupações finais do filósofo. U ma das dificuldades mais importantes no trabal ho de interpretação dessa noção, e talvez até mesmo a chave para a sua compreensão, reside na escolha de uma dentre as duas formas gramaticais em que essa noção se apresenta nos textos do filósofo: "formas devida", no plural, ou "forma de vida", no singular.

$\mathrm{N}$ a primeira leitura, queé também a mais difundida, o termo élido no plural. N esse caso, teríamos várias formas de vida diferentes e os indivíduos que pertencessem a formas de vida diferentes estariam numa situação de conflito radical, ${ }^{2}$ ou seja, eles não poderiam se compreender mutuamente. $N$ esse caso, porém, teríamos o problema de como reconhecer uma outra forma de vida como diferente, mesmo sendo incapazes de compreender o outro falante. Passaremos a nos referir a esse impasse como o problema do solo comum.

Na leitura singular, teríamos apenas uma única forma de vida humana. De acordo com essa segunda leitura, não haveria possibilidade de conflitos envolvendo dois ou mais indivíduos que participassem de formas de vida diferentes, uma vez que, ao usarem uma linguagem, esses indivíduos estariam participando de uma mesma forma de vida humana e teriam, portanto, algo em comum. Embora nessa segunda leitura não apareça o problema do solo comum, ainda permaneceríamos com o problema de esclarecer 0 que acontece nessas situações especiais em que observamos um conflito radical e o de como resolvêlas. 
Para tentar esclarecer as vantagens e desvantagens de cada opção, investigaremos quatro possíveis interpretações para o termo "forma de vida", apresentando também as implicações que essas diferentes interpretações terão na solução do nosso impasse. As quatro interpretações que proporemos a seguir são: $1^{\mathrm{a}}$ - formas de vida como "jogos de linguagem" (plural); $2^{\mathrm{a}}$ - formas de vida como "manifestações orgânicas" (plural); $3^{a}$ - formas de vida diferentes como "culturas diferentes" (plural); $4^{\text {a }}$ - uma única forma de "vida humana" (singular).

\section{As INTERPRETAÇõES}

"Formas de vida" como "jogos de linguagem"

A primeira interpretação considera que as noções de "formas de vida" e "jogos de linguagem" poderiam ser usadas de uma forma mais ou menos sinônima: dar exemplos de formas de vida seria dar exemplos de jogos de linguagem. A equiparação entre essas duas noções ("formas de vida" e "jogos de linguagem") teria uma grande vantagem: a noção de "jogos de linguagem" é muito mais bem explicada na obra publicada de W ittgenstein, e suas ocorrências são muito mais freqüentes. A principal passagem que suporta essa primeira interpretação é o parágrafo 19 das IF :

É fácil imaginar uma linguagem que consista apenas de comandos e informações durante uma batalha. - 0 u uma linguagem que consista apenas de perguntas e de uma expressão de afirmação e de negação. E muitas outras. E imaginar uma linguagem é imaginar uma forma de vida.

Essa passagem é considerada pel os defensores dessa primeira interpretação como sendo o Lócus Clássicus no qual Wittgenstein falaria de modo mais claro a favor de uma identidade entre os dois conceitos. Embora, nesse trecho, a ligação seja en tre o termo "linguagem" e o termo "forma de vida" ("[...] imaginar uma linguagem é 
imaginar uma forma de vida"), os exemplos de linguagem dados por W ittgenstein são apresentados em outras passagen s como exemplos de jogos de linguagem, o que nos permitiria concluir que "imaginar um jogo de linguagem é imaginar uma forma de vida".

Com efeito, em diversas passagens, W ittgenstein considera os jogos de linguagem como linguagens. No L ivro azul, por exemplo, W ittgenstein afirma que estudar jogos de linguagem é estudar formas primitivas de linguagem ou linguagens primitivas: "O estudo dos jogos de linguagem éo estudo de formas primitivas da linguagem ou de linguagens primitivas" (LA, p. 47).

$\mathrm{Se}$, no caso da passagem 19, imaginar uma linguagem fosse imaginar uma linguagem primitiva, poderíamos utilizar as duas expressões, "linguagem" (tomada como uma linguagem primitiva) e "jogos de linguagem", da mesma maneira. Esse movimento interpretativo que considera o termo "jogos de linguagem" como linguagens primitivas traria a vantagem de esclarecer a sugestão de W ittgenstein, qual seja a de que poderíamos imaginar uma linguagem composta apenas de coman dos e de informações, numa batalha. Se estivermos imaginando uma linguagem primitiva, na passagem 19 , poderíamos facilmente imaginá-la como sen do composta apenas de comandos e informações numa batal ha.

W ittgenstein, no entanto, também aceita identificar uma linguagem "completa" (ou não primitiva) como o jogo de linguagem. No parágrafo 7 das I nvesti gações filosóficas, o filósofo austríaco afirma que, além de indicar uma linguagem primitiva, a expressão "jogos de linguagem" poderia se referir também ao todo constituído pela linguagem e pelas ações a ela ligadas.

Também podemos conceber que todo o processo do uso de palavras [...] seja um daqueles jogos por meio dos quais as crianças aprendem a sua língua natal. A estes jogos quero chamar jogos de linguagem e falarei por vezes de uma linguagem primitiva como sendo um jogo de linguagem.

[...] 
Chamarei também ao todo formado pela linguagem com as atividades com as quais ela está entrelaçada o jogo de linguagem. (IF, § 7)

Embora essa passagem reforce a primeira interpretação, ao estabelecer uma identidade entre a expressão "jogos de linguagem" e a expressão "linguagem" (nas suas duas acepções), temostambém um terceiro elemento que é apresentado como integrante da noção de "jogo de linguagem" na sua segunda acepção: as atividades com as quais alinguagem estaria "entrelaçada". A sugestão de que poderíamos denominar o todo formado pela linguagem e pelas atividades a ela relacionadas como "o jogo de linguagem" parece indicar que W ittgenstein estaria disposto a aceitar que, quando falamos em "0 jogo da linguagem", estamos considerando não só a linguagem, mas também as atividades com as quais ela estaria entrelaçada.

A partir da leitura de algumas passagens (IF, § 19; LA, p.47; IF, §7), podemos concluir ser possível usar a expressão "jogos de linguagem" no lugar de "linguagem", tanto para indicar que consideramos como linguagem as linguagens primitivas, como para indicar o grande todo composto de linguagem e ação. 0 u seja, poderíamos fazer a substituição e dizer que "imaginar um jogo de linguagem seria imaginar uma forma de vida". No entanto, embora concordemos que essa substituição seja viável, não acreditamos que essa seja a melhor opção para interpretar o §19. A possibilidade alternativa relevante no caso é que o verbo "ser" não esteja sendo usando no sentido de igualdade, mas sim no sentido de subordinação. Com efeito, a partir do fragmento em questão, não poderíamos logicamente inferir que as expressões "jogos de linguagem" e "formas de vida" sejam necessariamente interdefiníveis. A interpretação que parece mais compatível com as outras passagens que apresentamos é a de que W ittgenstein queira dizer simplesmente que, quando imaginamos uma linguagem, somos levadosa imaginar as atividades que dão origem a ela, somos levados a imaginar uma forma de vida. Como fica bem claro na passagem 7 das I nvestigações filosóficas, 
a expressão "jogos de linguagem" tanto pode ser usada para indicar linguagens primitivas, como a relação entre o todo da linguagem e as atividades que estão entrelaçadas a ela. Essa interpretação en contra apoio na passagem 23, pois nela W ittgenstein emprega claramente o termo "jogos de linguagem" justamente como um elo entre "linguagem" e "atividade ou forma de vida", considerando a linguagem como uma parte de uma forma de vida: "Aqui o termo 'jogos-de-linguagem' tem o sentido de trazer à tona o fato de que 0 falar uma linguagem é parte de uma atividade, ou de uma forma de vida" (IF, § 23. Grifo meu).

Essa passagem parece ter o objetivo de realçar a estreita conexão entre falar uma linguagem e estar imerso em uma situação no mundo. A o se referir à linguagem como uma parte de uma forma de vida, W ittgenstein estaria sugerindo que a linguagem não envolveria apen as a fala, mas também outras atividades. Assim, quando falamos de jogos de linguagem, estamos nos referindo aos múltiplos usos da linguagem que fazem da nossa fala uma fala com sentido. A satividades, ou os múltiplosusos, por sua vez, são aspectos da nossa forma de vida. Essa conclusão é sustentada também pelas outras ocorrências do termo "forma de vida". N as passagen sem que esse termo aparece, podemos observar uma preocupação de W ittgenstein em se referir a algo mais fundamental sobre o qual a linguagem cresceria. Assim, enquanto falamos de jogos de linguagem, podemos ainda nos referir à forma de vida como o meio no qual os jogos de linguagem estão imersos; já quando falamos em formas de vida, parece que não podemos seguir adiante. De alguma maneira estamos diante de algo "dado", algo tão fundamental como "realizar uma ação" ("C ause and effect: intuitive awareness", PO , 21/ 10/ 1937). É o ponto onde "a nossa espada entortaria" (IF , § 217).

\section{A "ABORDAGEM ORGÂNICA"}

De acordo com a segunda interpretação, o termo "forma de vida" seria compreendido biologicamente, e a situação biológica e orgânica de um indivíduo seria a sua forma de vida. Q uem primeiro 
sugeriu interpretar a noção de "forma de vida" desse modo foi J. F. M. H unter num artigo chamado "'Forms of life' in W ittgenstein's Philosophical investigations". Segundo essa abordagem, falar ou usar uma linguagem seria uma prática comportamental de elevada complexidade, a ser realizada por seres humanos sem a necessidade de pré-requisitos. Em outras palavras, falar é al go que fazemos sem pensar e, portanto, estaria no mesmo nível de outros comportamentos biológicos complexos que são realizados dessa mesma maneira, como comer, andar, beber e brincar. Ele chama a sua abordagem de "abordagem orgânica" - "the organic account" H unter (1971, p. 278) - e procura colocá-la como uma alternativa àsjá existentes. No entanto, o filósofo admite que a sua "abordagem orgânica" seja de difícil defesa, já que não é comum incluir aquilo que é aprendido - o comportamento inteligente, a vontade e tudo o que se passa na mente de um indivíduo em geral - como algo orgânico ou biológico.

Segundo H unter, a sua "abordagem orgânica" possui três aspectos importantes. 0 primeiro deles diz respeito à maneira como apreendemos ou somos treinados em uma língua. $\mathrm{Na}$ "abordagem orgânica", o treinamento de uma língua seria semelhante ao treinamento que realizamos quando, por exemplo, aprendemos a dançar. A ênfase na idéia de treinamento, nessa abordagem, traz à tona uma característica da noção de "forma de vida" que é assinalada por W ittgenstein em muitas passagens das I nvestigações filosóficas (§ $5,6,9,86,143$ ) e do Sobre a certeza ( $\$ 434$ ):

U ma criança usa tais formas primitivas de linguagem quando aprende a falar. A qui 0 ensino de uma linguagem não é uma explicação, mas treinamento. (IF, § 5)

$M$ as se uma pessoa não possuir, ainda, os conceitos, eu a ensinarei a usar as palavras através de exemplos e pela prática. - $\mathrm{E}$, ao fazêlo, não Ihe transmito menos do que eu próprio sei. $(\mathrm{IF}, \S 208)$ 
0 aprendizado de uma linguagem se daria por procedimentos de treinamento e conversão, enão por argumentação. N a passagem 208, podemos observar também que esse treinamento seria uma prática que se caracterizaria por não envolver procedimentos de justificação. N ão "explicamos" regularidades; elas semostram através do modo como fazemos e de exemplos. $N$ as passagens abaixo, podemos encontrar referências a esses procedimentos que estariam na base do aprendizado de uma língua. Eles seriam modos de agir, fatos da vida, ou formas de vida.
[...] o fato de que agimos de tais e tais maneiras, e.g., punimos certas ações, [...] damos ordens, [...] descrevemos cores, temos interesse nos sentimentos de outros. 0 que tem de ser aceito, o dado - poderíamos dizer - são fatos da vida (lebensformen). (RPP, I-630)
0 aceito, 0 dado - poder-se-ia dizer - são formas de vida. (IF, parte II, seção 11, p. 226. G rifo meu)

Podemos observar também que esses procedimentos nos são transmitidos quando somos treinados, imersos em uma forma de vida, e não através de argumentos. "Correto e falso é o que os homens dizem; e na linguagem os homens estão de acordo. Não é um acordo sobre as opiniões, mas sobre a forma de vida" (IF , § 241. Grifo meu).

Para H unter, quando W ittgenstein sugere um acordo, ele não está se referindo a um acordo convencional, mas à constatação de que agimos de tais e tais maneiras, eque esse modo de agir é "dado". A "abordagem orgânica" esclareceria, portanto, uma característica importante para W ittgenstein na noção de "forma de vida": a idéia de treinamento. Q uando queremos falar alguma coisa, não "planejamos e executamos" (H unteR, 1971, p. 279), apenas falamos. D e fato, falar envolveria um condicionamento do organismo num nível biológico de respostas que faria do procedimento algo que faríamos sem pensar, algo fisiológico, num certo sentido. 
0 segundo aspecto frisado por H unter é que a sua "abordagem orgânica" reduziria a utilização apropriada da linguagem a um reflexo fisiológico, algo próximo do ato de tirar a mão de um objeto quente. A penas retrospectivamente e com um objetivo explicativo, poderíamos dizer que tivemos alguma "intensão" ao falar. Esse segundo aspecto poderia esclarecer, segundo H unter, as críticas de W ittgenstein à visão tradicional da linguagem. $\mathrm{N}$ a visão tradicional, a linguagem seria um elemento intermediário entre as idéias e as coisas. Já na "abordagem orgânica", sugerida por H unter, a linguagem não seria esse terceiro elemento, el a surgiria diretamente da prática, sem a necessidade de entidades mentais intermediárias.

0 terceiro aspecto da abordagem orgânica que Hunter considera vantajoso é o que ele chama de "tese da auto-suficiência lingüística". Essa tese reza que não precisamos, e não utilizamos normalmente, nenhuma espécie de parafernália psicológica para dizer coisas com sentido. N ovamente, a interpretação sugerida por $\mathrm{H}$ unter vem esclarecer aquilo que é dito por W ittgenstein (IF, § 449 e 503) , ou seja, não precisamos de nenhuma explicação para entender o que uma pessoa diz, mas o que ela diz é simplesmente 0 que ela está dizendo.

H unter aponta dois ganhos importantes da sua tese da autosuficiência lingüística. 0 primeiro é que, ao eliminar a necessidade de uma metalinguagem para explicar a linguagem comum, a tese da auto-suficiência lingüística produz um alívio na pressão exercida pela necessidade de regras para uma fala bem-sucedida, mostrando assim como poderíamos prosseguir sem elas. 0 segundo ganho é mais bem compreendido em contraste com a visão tradicional da linguagem. $\mathrm{N}$ a visão tradicional, a linguagem seria uma evolução artificial do homem e viria ao encontro da necessidade de expressar sentimentos e desejos. $\mathrm{Na}$ teoria da auto-suficiência lingüística, a linguagem éalgo natural no homem; não estamos expressando al go prévio e não-lingüístico, mas realizando uma ação especializada.

H unter observa que uma possível má interpretação da sua teoria seria vêla como um mapeamento explicativo de como, 
fisiologicamente, os atos se realizam. Existiria aqui um ponto de ruptura. Não queremos descer a mais explicações; 0 interessante dos processos orgânicos é que eles simplesmente funcionam.

U ma outra objeção possível a essa versão é que ela parece deixar de lado o contexto social. Esse é o principal ponto de discordância entre Hunter e alguns dos outros comentaristas de W ittgenstein. Estes últimos optam por considerar qualquer atividade (a linguagem, por exemplo) como um acontecimento organizado dentro de uma comunidade, um padrão que foi aceito por todos, ou por um grupo. Para esses filósofos, na linguagem, 0 ato social é realçado no lugar da ação do indivíduo. G ertrude Conway defende esse ponto de vista. Ela insiste que, justamente por envolver um padrão aceito por todos, a linguagem não pode ser entendida como uma ação individual. Para a filósofa, 0 argumento contra a possibilidade de uma linguagem privada é justamente o que marca a dimensão social que está por trás de todo uso da linguagem. A questão de como seguir uma regra teria uma única resposta: seguimos desta e não daquela maneira, por uma questão de acordo dos falantes. Não pode haver "um seguir" particular de uma regra, pois não haveria parâmetros para decidir o que é seguir a regra corretamente. A ausência de parâmetros, segundo C onway, antes de transformar cada falante na sua própria medida, nos levaria a buscar fora do indivíduo um consenso que o levasse a utilizar as palavras desta ou daquela maneira.

Embora concordemos que Hunter considera a sua posição favorável à ausência de critérios de significados coletivos, não acreditamos que ele esteja defendendo que existam parâmetros particulares para seguir uma regra, como entende Conway, mas sim que não necessitamos de quaisquer parâmetros ou regras, externos ou internos, uma vez que a linguagem estaria dentro de cada indivíduo como uma reação natural. A esse respeito, $H$ unter alega que podemos considerar uma atividade qualquer de duas diferentes maneiras: como um acontecimento organizado dentro de uma comunidade ou como uma coisa particular, feita por um 
indivíduo, envolven do habilidades orgânicas. H unter considera que o segundo modo de considerar uma atividade é aquele que W ittgenstein gostaria de enfatizar quando relaciona "Iinguagem" e "forma de vida". Para apoiar a sua posição, H unter nos remete, entre outros, ao parágrafo 219 das Investigações filosóficas: "Q uando eu obedeço a uma regra, eu não tenho escolha. Eu obedeço à regra cegamente".

H unter (1971, p. 293) entende que, nessa passagem, não é o modo como nós fazemos, mas "como eu faço", como cada um faz, queé "o dado" (IF, p. 226). Para ele, W ittgenstein estaria enfatizando o pronome pessoal na primeira pessoa justamente para se referir àquela segunda maneira de considerar uma atividade: uma coisa particular, feita por um indivíduo, envolvendo algum tipo de habilidade orgânica.

A linha de argumentação seguida por H unter se cruza com a discussão de Wittgenstein sobre a noção de regra, que muitos consideram como um argumento contra a possibilidade de uma linguagem privada. Esse argumento, atribuído a W ittgenstein, fala da impossibilidade de critérios de correção para a atribuiç̧ão de um significado privado a uma palavra, ou seja, um significado que não pode ser expresso lingüisticamente. Em diversas partes do seu texto, H unter considera como um ganho da sua "abordagem orgânica", bem como da sua "teoria da auto-suficiência lingüística" (que é um corolário da primeira), oferecer uma explicação de como não conseguimos encontrar esse critério empírico para seguir uma regra (H unter, 1971, p. 284 e 289). Essa busca não faria sentido porque, ao falarmos, estaríamos simplesmente nos comportando biologicamente. U m outro ganho é o de que não precisaríamos recorrer a uma interpretação comunitarista (que defendesse a existência de um acordo entre os falantes) para explicar a linguagem.

Embora seja meio fora do comum, a posição de $\mathrm{H}$ unter tenta dar conta de um aspecto muito importanteligado à noção de "forma de vida", a sua origem nas atividades humanas. Ainda assim, aceitamos a observação de C onway de que essa segunda interpre- 
tação não leva em consideração os aspectos culturais e, principalmente, que ela não menciona aquilo que as diferentes formas de vida teriam em comum. 0 problema que vemos na interpretação de Hunter é que cada ser humano teria a sua própria forma de vida, embora elas não fossem necessariamente muito diferentes entre si. $\mathrm{O}$ próprio $\mathrm{H}$ unter enten de que a sua interpretação seria apenas uma sugestão de trabal ho, eque o seu val or está em oferecer uma abordagem que privilegie 0 aspecto praxiológico da linguagem: “Estarei tentando mostrar, não tanto que a minha interpretação é fortemente recomendável, mas que ela também é uma concorrente de peso" (H UNTER, 1971, p. 286).

\section{"Formas DE VIDA" COMO CULTURAS DIFERENTES}

Segundo essa interpretação, descrever uma forma de vida seria descrever uma cultura. N esse caso, muitas pessoas estariam envolvidas em uma única forma de vida, e poderíamos falar em várias formas de vida do mesmo modo como falamos em várias culturas. Peter W inch e Vernon Pratt são autores que defendem essa posição. No texto "U nderstanding a primitive society", W inch realiza um estudo sobre as diferentes maneiras de abordar uma cultura estrangeira com uma concepção de realidade completamente diferente da nossa. A discussão queW inch estabelece com a antropologia diz respeito ao modo como avaliamos essa outra cultura. A dificuldade dessa avaliação está, segundo W inch, em estabelecer diferentes padrões de racionalidade, sem, no entanto, abandonar o nosso próprio ponto de vista. É nesse contexto que W inch critica o conceito de realidade que norteia os estudiosos de sociedades humanas. Ele cita um trecho de Evans-Pritchard, no qual esse autor defende uma posição tradicional em relação a esse problema:

Mas nós podemos dizer que o conteúdo social do nosso pensamento sobre a chuva é científico, está de acordo com os fatos objetivos, enquanto o conteúdo social do pensamento 
do selvagem sobre a chuva é não-científico já que ele não está de acordo com a realidade. (Evans-Pritchard, 1934)

Assim como Evans-Pritchard, muitos daqueles que entraram em contato com uma cultura estrangeira defendem que, embora a mesma realidade possa dar margem a diferentes culturas que possuiriam suas próprias lógicas internas, seus próprios critérios de racionalidade, muitas delas não estariam "de acordo com a realidade". Segundo esse autor, haveria uma única maneira de interpretar a realidade de maneira correta: o pensamento científico proposto pela nossa civilização. A pesar de discordar dessa posição, W inch admite que abandonar completamente a idéia de poder comparar as práticas humanas com uma realidade objetiva seria cair em uma espécie de relativismo com todos os paradoxos que essa posição implica.

U ma boa maneira de explicar o que seriam esses paradoxos é a de usar a metáfora dos diferentes pontos de vistas. Segundo essa metáfora, para observarmos uma cultura diferente, precisamos de um ponto de vista qualquer. U ma primeira opção seria a de adotarmos a nossa cultura como o ponto de vista correto. N esse caso, diríamos que nós estamos de acordo com a realidade como ela de fato é, mas a outra cultura, não. Poderíamos também adotar como ponto de vista os padrões da outra cultura como nossos. N esse segundo caso, também não estaríamos permitindo uma diversidade de pontos de vista, mas apenas considerando que somente a outra cultura estivesse de acordo com a realidade como ela de fato é. U ma terceira solução para esse impasse seria a de adotarmos um ponto de vista "neutro", que não favorecesse a nenhuma das duas culturas. Esse terceiro ponto de vista, no entanto, teria de consistir de traços comuns às duas culturas em questão, sob pena de um não compreender absolutamente 0 outro. 0 fato de que temos de ter algo em comum para compreender o ponto de vista do outro nos traz de volta ao problema que chamamos, no início deste artigo, "o problema do solo comum". 0 problema de ter um solo comum é 
que ele passaria a ser o ponto de vista de todos e, portanto, novamente, não poderíamos falar de pontos de vista diferentes. Em resumo, nenhuma das três alternativas nos levaria a reconhecer a possibilidade de pontos de vista diferentes que descrevam igualmente bem a realidade.

A proposta deW inch éa de que utilizemosa noção de "forma de vida" proposta por W ittgenstein para nos auxiliar na análise desses problemas. Essa noção nos ajudaria a compreen der o choque cultural entre esses diferentes povos, sem apelar para a posição "insustentável" do relativista. Segundo W inch, nesses casos, a maior dificuldade que temos de enfrentar é originada do fato de que a nossa "forma de vida" não dispõe dos conceitos necessários para compreendermos uma "forma de vida" diferente. Assim, ao estabelecermos contato com outra cultura, deveríamos ter, como ponto de partida, um outro solo comum, com conceitos pertencentes às duas culturas que nos permitisse compreendêla. Esse solo comum seria, portanto, mais fundamental que as formas de vida de cada um dos povos em questão.

0 candidato cogitado por W inch para ser esse solo comum é o que ele chama de "o sentido de racionalidade que é comum a qualquer cultura". O u seja, qualquer cultura faria sentido para aqueles que dela participassem e, portanto, cada uma delas teria 0 seu próprio sentido de racionalidade. Segundo Winch, em diferentes universos de discursos, teríamos diferentes modos de interação do homem com suas vivências, como a vivência mística e a científica, por exemplo. $M$ as, em todos eles teríamos presente uma noção própria do que faz e do que não faz sentido. A racionalidade de cada cultura seria expressa, portanto, no sucesso da comunicação humana através de uma linguagem, ou seja, na própria noção de "significado". Assim poderíamos proceder a uma inversão na ordem como víamos as coisas tradicionalmente e dizer: "o que é real e o que não é se mostra no sentido que a linguagem possui" (W INCH, 1970, p. 82). A conclusão de W inch, que aparece 
com clareza nesse trecho, éa de que, sempre que temos uma linguagem com sentido, temos algum conceito de racionalidade.

Racionalidade não é apenas um conceito numa linguagem como outro qualquer; [...]. Racionalidade é um conceito necessário para a existência de qualquer linguagem: dizer de uma sociedade que ela tem uma linguagem é dizer também que ela tem um conceito de racionalidade. (W INCH, 1977, p. 99)

Segundo o pensamento desse filósofo, a racionalidade seria uma espécie de condição de possibilidade para qualquer linguagem. Ela seria, portanto, uma espécie de solo comum através do qual poderíamos compreender outras culturas. Assim, diante de uma nova cultura, não precisaríamos de nos esforçar para determinar 0 queé ou não é racional dentro dela, mas apenas nos basear no fato geral de que todas elas possuem al gum critério de racionalidade.

W inch tenta explicar essa racionalidade através da idéia de que a vida teria um sentido comum a todos os seres vivos, "um sentido de significância da vida humana", que poderia ser encontrado em alguns princípios aceitos por todos, como nascimento, morte e procriação. Esses princípios se manifestariam nas regularidades a partir das quais formamos padrões de comportamento.

$\mathrm{N}$ a minha discussão sobre os ritos mágicos dos Azandes, eu tento relacionátos com aquilo que chamo de um sentido da significância da vida humana. Eu penso que esta noção é indispensável para qualquer consideração sobre o que está envolvido em compreender e aprender uma cultura estrangeira. (W INCH, 1977, p. 105)

A noção de "senso de significância da vida humana" vai ocupar um papel central na compreensão da idéia de racionalidade. Ela é desenvolvida por W inch como sendo uma habilidade de ver unidade e encontrar regularidade naquilo que fazemos. Essa habilidade de fazer sentido e de encontrar regularidades vai depender 
tanto da maneira como vivemos as nossas vidas como da maneira que as outras pessoas vivem as suas. A nossa tarefa, em seguida, seria traçar uma relação entre a concepção de racionalidade da sociedade que estudamos e a nossa concepção de racionalidade, acrescentando os parâmetros deles aos nossos para que possamos compreendêlos. Com isso estaríamos estenden do os limites do nosso modo de vida, e não simplesmente trazendo o modo de vida do outro para dentro dos limites já existentes no nosso.

Para que estudemos um outro modo de vida é necessário que procuremos estender o nosso próprio - não podemos simplesmente trazer o outro modo de vida para dentro dos limites já existentes do nosso modo de vida, porque o ponto fundamental a respeito do último é que ele, por hipótese, exclui o primeiro. (W $\mathrm{INCH}, 1977$, p. 99)

U ma vez que modos de vida, ou pontos de vista, ou ainda formas de vida diferentes, se excluem mutuamente, por hipótese, W inch conclui que só podemos estudar uma outra cultura se pudermos fazer uma extensão conciliatória dos limites do nosso modo de vida. A maneira como faremosisso éatravés do solo comum encontrado por ele: a necessidade de que a vida tenha um significado. Culturas diferentes teriam diferentes significados para a vida. N esses diferentes significados encontraríamos, entretanto, conceitos comuns que nos permitiriam falar de uma outra cultura, através de uma ampliação da nossa concepção do que é real e do nosso próprio sentido da vida.

U ma crítica que caberia aqui à noção encontrada por W inch para desempenhar o papel de solo comum é se não estaríamos transferindo para a noção de "senso de significância da vida humana" aquilo que antes atribuíamos à noção de "forma de vida". N esse caso, poderíamos recolocar todos os problemas gerados pela situação de conflito entre formas de vida diferentes para a nova noção. 0 u seja, como reconhecer que outras pessoas têm um "senso 
de significância da vida humana" diferente do nosso, se temos pontos de vista diferentes?

Essa pergunta é semelhante à que Wittgenstein se faz nos parágrafos 611 e 612 do Sobre a certeza. Lá W ittgenstein imagina como seria um conflito entre duas pessoas que pertencessem a formas de vida diferentes:

$\S 611$ Quando se encontram dois princípios que não podem conciliar-se um com o outro, os que defendem um declaram os outros loucos e heréticos.

$\S 612 \mathrm{Eu}$ disse que "combateria" o outro homem - mas não Ihe indicaria razões? Certamente; mas até onde é que chegam? No fim das razões vem a persuasão. (Pense no que acontece quando os missionários convertem os nativos.)

Segundo o filósofo austríaco, não poderíamos simplesmente apreender uma outra forma de vida, mas teríamos de ser educados dentro dela. Assim, não poderíamos incorporar os princípios de outra cultura, acrescentando-os à nossa, uma vez que essa incorporação significaria ver as coisas de modo diferente, e não mais do modo antigo: uma espécie de conversão. A menção à noção de "conversão", nesse último parágrafo, parece falar a favor da idéia de que ocorreria uma mudança na pessoa que se convertesse (no caso, o nativo), de tal maneira que ela abandonaria o seu antigo modo de argumentar, passando a defender o ponto de vista do outro, e não mais o seu.

Concluindo: o problema principal com essa terceira interpretação é que ela só resolve o problema do solo comum à custa da transformação da noção de "forma de vida" em algo trivial, e recorren do a uma outra noção, mais fundamental, que seria a noção de "significância da vida humana". Essa solução, no entanto, não leva em consideração uma das características mais importantes da noção de "forma devida", a de não ser justificável através de princípios de racionalidade. $\mathrm{O} u$, na mel hor das hipóteses, transfere o problema para a nova noção, queficaria agora no papel de "maisfundamental". 
A INTERPRetaÇão "Singular"

A quarta interpretação sustenta a leitura no singular para 0 termo "forma de vida". Seu principal defensor, Newton Garver, sugere, como única opção plausível, que W ittgenstein esteja se referindo a uma única forma de vida humana. Garver apóia a sua posição em quatro (IF , § 19, § 23, § 241 ep. 174) das cinco ocorrências do termo nas Investigações filosóficas - as que estão no singular embora ele também faça referência a outras cinco ocorrências do termo na obra publicada de W ittgenstein. ${ }^{3}$

G arver sustenta a sua interpretação de duas maneiras diferentes: por meio de apoio textual e de um argumento geral. Com relação às passagens nas quais aparece uma menção à noção de "forma de vida", G arver conclui que ou as pessoas que lêem o termo no plural leram errado, ou existe pelo menos uma outra versão da passagem no singular. Já o argumento geral desenvolvido por Garver diz respeito a um problema mais filosófico. Segundo esse argumento, só podemos falar coerentemente de uma única forma de vida humana, uma vez que a linguagem é um elemento comum a todos os seres humanos. Investigaremos em primeiro lugar os argumentos textuais para depois analisar o argumento geral.

U ma das objeções exegéticas levantadas por G arver se refere diretamente à passagem 19, aquela que investigamos na primeira interpretação. 0 argumento levantado por $\mathrm{G}$ arver é que, se nessa passagem, aceitássemos dizer que “imaginar uma linguagem é imaginar uma forma de vida", então a forma de vida associada à linguagem proposta por W ittgenstein não poderia ser humana, pois não seria possível a seres humanos se comunicarem com tão escasso vocabulário. Para G arver, o problema está em chamar de linguagem qualquer composição de sintaxe e palavras. Para ele, uma linguagem tem de estar integrada às atividades de algum tipo de ser vivo que real mente a use para se comunicar. Ao considerar a capacidade de usar uma linguagem como necessária e universal para a humanidade, Garver considera qualquer outra forma de vida que 
não tenha essa característica como não-humana, i.e., como formas de vida canina, bovina etc. (IF, p. 174 e 226; § 650, 250, p. 229, § 357, p. 223, § 206).

G arver apresenta ainda uma segunda objeção à interpretação pluralista da passagem 19. Ele diz que, tanto no caso de estarmos utilizando o texto da passagem 19 no original quanto no caso de substituirmos "linguagem" por "jogo de linguagem", estaríamos cometendo um erro lógico ao afirmar que "da premissa: quando eu imagino uma linguagem eu imagino uma forma de vida, [...] se siga que quando eu imagino duas linguagens eu imagino duas formas de vida" (G ARVER, 1994, p. 245). M esmo substituindo "uma linguagem" por "jogos de linguagem", poderíamos continuar mantendo a forma gramatical usada originalmente por W ittgenstein, ou seja, "imaginar jogos de linguagem é imaginar uma forma de vida". G arver vê também o $§ 23$ das I nvestigações fil osóficas como um outro exemplo desse tipo de engano. Segundo ele, a partir da frase "aqui 0 termo 'jogos-delinguagem' tem o sentido de trazer à tona o fato de que o falar uma linguagem é parte de uma atividade, ou de uma forma de vida", não podemos inferir que segunda parte (em itálico) se refira à mesma coisa que a primeira (também em itálico). Podemos e devemos entender a referência a jogos de linguagem no plural de maneira diversa da referência a uma "atividade" ou "forma de vida", que estariam, por sua vez, no singular.

A outra objeção exegética de $\mathrm{G}$ arver diz respeito à fidelidade das citações. Ele cita, entre outros, $C$ avell e Pitcher como exemplos. C avell teria escrito incorretamente que W ittgenstein "fala que a nossa habilidade de usar a linguagem depende de um acordo sobre 'formas de vida' (PI, 241)" (C AVELL, 1979, p. 30). Pitcher também teria se enganado ao apoiar a sua defesa da leitura no plural nas passagens § 19, §23 e p. 226 do IF (G ARVER, 1994, p. 242). Segundo $G$ arver, W ittgen stein só teria utilizado o plural em uma única dessas passagens, a da página 226 do IF. ${ }^{4} \mathrm{E}$, quanto a essa única passagem, Garver acredita que ela não seja "boa". A primeira razão é que ela tem a forma de uma sugestão (tanto por causa da forma subjuntiva 
do texto em alemão quanto pelo uso da expressão "poderíamos dizer"). E a segunda é que existe uma passagem similar (RPP, I-630) na qual encontramos "fatos da vida" no lugar de "formas de vida". ${ }^{5}$ A sugestão de Garver é que Wittgenstein estivesse em dúvida a respeito do emprego de uma das seguintes expressões: "formas de vida" ou "fatos da vida", e que ele finalmente teria escolhido a segunda opção.

Se a passagem da página 226 é um mau exemplo, que deve ser pouco considerado, a passagem da página 174 émuito importante para Garver. N ela, W ittgenstein parece ligar definitivamente a noção de "forma de vida" à capacidade de falar.

A penas quem fala pode ter esperança? A penas aquele que domina o emprego de uma linguagem. Isto é, os fenômenos da esperança são modificações desta complicada forma de vida. (Se um conceito visa a um caráter de escrita humana, não tem nenhuma aplicação com seres que não escrevem). (IF, p. 174)

Para Garver, essa "complicada forma de vida" à qual W ittgenstein se refere é a forma de vida humana. Ela envolve todos aqueles fenômenos anteriormente descritos como dar ordens, perguntar, contar, nomear e outros. A forma de vida humana seria a única a que $W$ ittgen stein poderia estar se referindo quando escreve que "apenas aqueles que dominam uma linguagem" podem ter esperança, eque "os fenômenos da esperança são modificações dessa complicada forma de vida". Partindo da premissa de que só poderíamos atribuir linguagem a seres humanos, G arver considera essas duas características - ser um ser humano e ter linguagem - como inseparáveis e como critérios uma para a outra.

No entanto, embora possamos concluir da passagem citada que "apenas aquel eque domina o emprego de uma linguagem pode ter esperança" (pode jogar o jogo de linguagem da esperança), disso não se poderia inferir que todos aqueles que dominam uma linguagem tenham esperança e sejam humanos, como Garver (1994, p. 253-254) parece concluir no seguinte trecho: 
Existe apenas uma alternativa [de interpretação] permitida pelo texto, que a forma de vida referida seja a daqueles que podem falar. E isso só pode significar a forma de vida determinada pelo domínio do uso de uma língua.

A conclusão de Garver é no mínimo precipitada, uma vez que W ittgenstein não está excluindo a possibilidade de uma forma de vida que não apresente o fenômeno da esperança, mesmo tendo linguagem, ou de seres humanos que não dominem o uso da linguagem, ou mesmo, como sugere H unter (1971, p. 290), que possamos dominar o emprego da expressão "esperar" sem nunca ter experimentado esse sentimento.

G arver conclui sua análise exegética das citações das I nvestigações filosóficas argumentando que, nas três últimas passagens (§ 241, p. 174 e 226), a expressão "forma de vida" é usada como um ponto final para qualquer investigação sobre justificativas, e que os exemplos dados são os de atividades humanas comuns a toda a espécie.

0 aspecto de ser "um ponto final", posto em evidência pelo fato de só haver uma forma de vida possível, é um ponto positivo da interpretação de G arver que as outras interpretações não apresentam. No entanto, em relação ao outro problema - como explicar situações de conflito radical - , a posição de G arver é menos interessante. Garver procura responder a essa acusação dizendo que, quando W ittgenstein escreve na passagem da página 223 das IF que "um ser humano pode ser um completo enigma para um outro", e na passagem 194 das IF que "quando fazemos filosofia somos como selvagens, pessoas primitivas, que ouvem as expressões do homem civilizado, colocam uma falsa interpretação nelas e depois tiram as mais estranhas conclusões", fica claro que esse desentendimento é muito mais o resultado de não termos aprendido costumes semeIhantes do que de uma incapacidade de aprendêlos (G ARVER, 1994, p. 247). Não estaríamos, para Garver, diante de uma ruptura de sentido, mas sim diante de uma mera diferença de opiniões.

A conclusão a que chega G arver, após a sua longa análise, éa de que só teríamos uma única linguagem para toda a raça humana. 
Para defender essa tese, no entanto, G arver precisa da hipótese de que uma linguagem só pode ser compreendida como um todo completo e, portanto, não podemos conceber "jogos de linguagem" como linguagens diferentes ou primitivas. Esse argumento nos leva de volta à discussão sobre o que consideramos "linguagem". G arver só admite que consideremos linguagem al go que seja produzido por seres humanos reais. Assim, nos exemplos que apresentamos na primeira interpretação, W ittgenstein estaria enganado ao chamar de linguagem qualquer atividade regida por regras em que pessoas estão se comunicando, como no caso da "linguagem de comandose ordens". O sargumentos de G arver, contudo, não são muito convincentes, pois podemos encontrar com facilidade um parágrafo que Ihes ofereceriam uma ótima réplica.

$\mathrm{N}$ ão te deixes perturbar pelo fato de que as linguagens (2) e (8) consistem apenas de ordens. Se queres dizer que, por esse motivo não são completas, então pergunta-te se a nossa linguagem é completa: - Se o era antes de a notação da Q uímica e de a notação do cálculo infinitesimal terem sido nela incorporados, uma vez que estes são, por assim dizer, os subúrbios da nossa linguagem... (IF, § 18)

W ittgenstein vem aqui nos lembrar que não é razoável supor que uma linguagem seja uma estrutura completa e acabada. A questão da completude ou incompletude dos jogos de linguagem (e da linguagem) também é abordada na passagem seguinte. N ela são apresentadas situações imaginárias como exemplos de linguagens completas.

Não consideramos, contudo, os jogos de linguagem como partes incompletas de uma linguagem, mas como linguagens completas em si mesmas, como sistemas completos da comunicação humana. Para manter presente este ponto de vista é, muitas vezes, útil imaginar esta linguagem simples como constituindo o sistema completo de comunicação de uma tribo, 
num estágio primitivo da sociedade. Pensem na aritmética primitiva dessas tribos. (LC, p. 14)

N essa passagem, W ittgenstein afirma que os jogos de linguagem são considerados como sistemas completos de comunicação, com uma ressalva: completo não significa acabado. Para melhor compreendermos o que seria algo completo, mas não acabado, W ittgenstein sugere que imaginemos uma tribo num estágio primitivo, onde a linguagem fosse mais simples, mas nem por isso deixasse defuncionar como uma linguagem. 0 argumento que $W$ ittgenstein quer elaborar com esse exemplo é o de que, para que algo seja considerado como linguagem, não seria necessário que fossem incluídas as possi bilidades complexas de expressão, uma vez que no exemplo mais simples já temos uma atividade regulada por regras e, portanto, por uma linguagem, ou por um jogo de linguagem.

Segundo W ittgenstein, podemos falar em várias linguagens e, portanto, se queremos colocar a noção de "forma de vida" como o nosso ponto final, não podemos identificála com "linguagem" como faz $\mathrm{G}$ arver. 0 problema que estamos enfrentando novamente é o problema do solo comum. No caso de G arver, esse solo comum parece ser a própria linguagem. Se acompanharmos G arver, considerando que temos uma única linguagem "completa" e universal, e que qualquer outra linguagem, ou pode ser traduzida nela, ou é uma linguagem imaginária, então não temos alternativa senão atribuir a todos os seres humanos uma mesma linguagem e uma mesma forma de vida. Se, no entanto, considerarmos como linguagem toda atividade com propósitos comunicativos que for regida por regras, teremos em aberto a possibilidade de nos depararmos com linguagens que sigam regras bem diferentes uma das outras.

CONCLUSÃO

O que obser vamos nessa investigação é que existe um impasse sobre qual seria a melhor interpretação para a noção de "forma de 
vida". D ois aspectos são relevantes nesse impasse: o fato de a noção de "forma de vida" ser um ponto final para os nossos argumentos, e a constatação de que muitas vezes encontramos certos conflitos que parecem envolver "formas de vida" diferentes. Assim, se quisermos defender a leitura no plural e, ao mesmo tempo, manter a idéia de que a noção de "forma de vida" seria um ponto final para o procedimento argumentativo, teremos de procurar o nosso solo comum dentro dessa própria noção. Em busca de uma solução para esse impasse, sugerimos recorrer a um aspecto fundamental da noção de "forma de vida": envolver atividades não-lingüísticas. A referência a uma atividade ou forma de vida nos permitiria enfocar a relação entre a linguagem e as situações nas quais fazemos os nossos proferimentos. Assim, ao usar a expressão "formas de vida", W ittgenstein estaria incorporando à linguagem justamente essas situações interpessoais que, apesar de múltiplas, não seriam ainda linguagem, não envolvendo, portanto, argumentos. D essa forma, os conflitos radicais poderiam envolver uma situação de ruptura que fosse a respeito de algo não-lingüístico, porém objetivo.

ABSTRACT: The main goal of this paper will be to elucidate the role performed by the notion "form of life" in the writings of Ludwig W ittgenstein. As a background for that discussion we will always keep in mind the question whether we should use the term "form of life" in the plural or in the singular form. We will critically investigate four possible interpretations offered by different scholars on W ittgenstein's sphilosophy. Each one of them will emphasize different aspects of the notion of a "form of life".

Key words: Forms of life, W ittgenstein, language games.

\section{Notas}

1. Cinco vezes nas IF (Investigações filosóficas): § 19, 23, 241, p. 174, 226; uma no SC (Sobre a certeza): §358; duas no ensaio "C ause and effect: intuitive awareness" (21/ 10/ 1937 e22/ 10/ 1937); uma no RFM (Remarks on foundation of mathematics): seção VII, §47; e uma no RPP (Remarks on the philosophy of psychology): parte I, passagem 630. 
2. W ittgenstein menciona, nas passagens 611 e 612 do Sobre a certeza. um conflito muito sério entre dois indivíduos que partem de princípios completamenteantagônicos. Ao tratar desse conflito, trazà tona certas características que parecem envolver a noção de "forma de vida". A suspeita é a de que, em al guns casos especiais, não estaríamos simplesmente discordando, mas sim diante de uma forma de vida diferente. N essa situação, os nossos argumentos não fariam efeito e teríamos de apelar para o método da conversão.

3. Garver cita apenas nove das dez ocorrências do termo "forma de vida" na obra publicada de W ittgen stein.

4. Garver não considera relevantes as outras ocorrências em que o termo "formas de vida" aparece no plural,

5. A palavra "formas" se encontra nas notas como uma alternativa para "fatos" nessa passagem.

\section{Referências}

C avell, Stanley. The claim of reason. New York: Oxford U niversity Press, 1979.

Conway, G ertrude D. Wittgenstein on foundations. A tlantic $\mathrm{H}$ ighlands. N ew Jersey: H umanities Press International, 1989.

EvANSPRITCHARD, E. E. Lévy-Bruhl's theory of primitive mentality Bulletin of the Faculty of Arts, U niversity of Egypt, 1934.

G arver, N ewton. This complicated form of life. Chicago: 0 pen Court Publishing Company, 1994.

Hunter, J. F. M. Forms of life in Wittgenstein's Philosophical investigations. Essays on W ittgenstein. Edited by E. D. Klemke. C hicago: U niversity of Illinois Press, 1971.

PITCHER, George. Wittgenstein: the philosophical investigations. Garden City, N ew York: Anchor Books, 1964. 
W INCH, Peter. The idea of a social science and its relation to philosophy. Atlantic H ighlands: H umanities Press, 1977.

Wittgenstein, Ludwig. Da certeza (SC). Tradução de Maria Elisa Costa. Lisboa: Edições 70.

. Investigações filosóficas (IF). Tradução de José Carlos Bruni. São Paulo: A bril Cultural, 1984. (O s Pensadores)

. Last writings on the philosophy of psychology: the inner and the outer (LW PP). v. II. Cambridge: Blackwell, 1992.

. Philosophical occasions 1912-1951 (PO). Edited by James Klagge e Alfred Nordmann. Indianopolis and Cambridge: Hackett Publishing Company, 1993.

. Remarks on the philosophy of psychology (RPP). v. I ell. Edited by G. H. von Wright and Heikki Nyman. Translated by C. G. Luckhardt e M. A. Aue. Oxford: Blackwell, 1980. 70, 1992.

. 0 livro azul (LA ). Tradução de Jorge M endes. Lisboa: Edições . 0 livro castanho. (LC). Tradução de Jorge M arques. Lisboa: Edições 70, 1992. 